(March, 1907) of the right elbow and of part of the chest point to there being extensive gummatous disease of the rigbt clavicle and lower end of the right humerus. ${ }^{25}$

Gummatous disease of periosteum and bone is certainly at times associated with fever. T. D. Savill ${ }^{26}$ has recorded a fatal case of congenital syphilis in a boy, aged 15 years, with extreme cachexia simulating pernicious anæmia, the necropsy showing gummatous masses over the frontal portions of the brain and gummatous disease of the petrous bone, ribs, and clavicle. In Savill's case the pyrexia was of an intermittent type, rising to $100^{\circ}-102^{\circ}$ in the evenings. Although my cases showed obvious changes in the abdominal viscera or bones, there may doubtless be cases of long-continued, apparently "idiopathic," pyrexia, in which on examination no signs of organic disease can be found to
account for the fever, but which may really be connected with tertiary syphilitic changes in the viscera in situations where such changes would escape detection by the ordinary methods of physical examination. In January, 1906, I saw a man, 45 years of age, who had suffered from primary and secondary syphilis in 1889. He had been treated at Aix-laChapelle in 1898 and about 1902. He had suffered from evening fever $\left(100^{\circ}-101^{\circ}\right)$ for about five months from July, 1905, but this fever had just disappeared on his voyage home from India. He complained of a little discomfort in the hepatic region, but $I$ could find no physical signs of any disease, except slight wheezing over the lungs, and there was a history of asthmatic symptoms. I regarded the chronic pyrexia as being very likely connected with his syphilis and the medical man at Aix-la-Chapelle, to whom at my advice he went for another course of antisyphilitic treatment, thought that it was connected with perihepatitis. It is very probable that in some cases of tertiary syphilitic fever the fever may cease without antisyphilitic treatment, just as gummatous disease may in some cases heal up without any specific measures being adopted. L. D'Amato ${ }^{27}$ writes amongst his conclusions that syphilitic fever may cease spontaneously without specific treatment, but then, just like the other syphilitic manifestations, it is more likely to recur. I have lately been looking over some notes of a case of a long-lasting pyrexia of unknown origin in which recovery ultimately took place but in which I regret that antisyphilitic methods were not given a fair trial. The patient, a man then aged 54 years, was admitted under my care on Nov. 15th, 1898, with a history of four weeks' illness and the fever, which was of intermittent or remittent type and associated with rigors, lasted till Dec. 21st. Malarial parasites were not found in the blood and he did not react to quinine and no satisfactory explanation of the fever was forthcoming. He had some oedema of the lower extremities, crepitations at the bases of the lungs, temporary slight enlargement of the liver, and superficial glossitis; there was a history of a chancre ten years years previously. This man was again temporarily under treatment in March and April, 1899. He then had slight jaundice, with crepitations at the base of both lungs and decided dulness at the base of the right lung. But on that occasion there was scarcely any fever (the temperature never reached $100^{\circ}$ except on the first evening) and the jaundice and the pulmonary signs readily cleared up. At present (1907) I hear that he is in fairly good health.

Harley-street, $\mathbf{W}$.

\section{A RADIOGRAPHIC SURVEY OF 170 CASES CLINICALLY DIAGNOSED AS "COLLES'S FRACTURE."}

\author{
By REGINALD MORTON, M.D., C.M. Trin. Tor., \\ F.R.C.S. EDIN., \\ MEDICAL OFFICER IN CHARGE OF THE ELECTRICAL DEPARTMENT, \\ LONDON HOSPITAL
}

STATISTICS regarding any disease or injury are always of interest and value to medical men, especially when the figures are based on the careful observation of a relatively large number of cases, and among fractures probably no single one possesses such a widespread interest among the profession as that of the lower end of the radius close to its articulation with the carpus, which is generally known, after

25 The red corpuscles have now (March 12th) increased to 5,000,000 in the cubic millimetre and the patient has quite lost his former appearance of cachexia. There has been no fever since March 1st. 26 Loc. cit. the surgeon who first described it, as "Colles's fracture." Until the advent of the $x$ rays it will be remembered that many points regarding it were the subjects of considerable controversy, such as the distance of the line of fracture from the carpal border or the character of the displacement. Before 1895 we were never taught that damage to the styloid process of the ulna was a common accompaniment of this injury ; in the several books published in the pre-Roentgen ray days which $I$ have consulted it is not even mentioned. This is not surprising when we consider the necessary imperfections of clinical examination and also the fact that the opportunity for making a dissection seldom arose. Roentgen's discovery has changed all this, and thanks to the work of Lynn Thomas and others new and valuable evidence has been forthcoming.

Considering the large amount of material available at the hospital with which I have the honour to be con. nected, it seemed advisable to make an attempt to obtain some more or less reliable data, and accordingly instructions were given to the receiving room officers to send all cas $\in \mathbf{s}$ diagnosed as Colles's fracture to be radiographedpreferably before being put up. This was carried out as systematically as possible for about 12 months, and it was in only a comparatively few cases--those arriving between Saturday evening and Monday morning, when the radiographic department was closed-that the radiograph was taken while the dresssing was in place. Owing to the large amount of practice obtained by the receiving room officers before and during their term of office, their skill in diagnosis may be taken as at least equal to that of the profession generally, and it may also be taken that in every case the history, signs, and symptoms, so far as could be elicited, pointed to the presence of this form of fracture. The radiographic procedure presented no special features. By screening one-half of the plate with a piece of sheet lead it was easy to get an anterior and an ulnar view side by side on a $8 \frac{1}{2}$ by $6 \frac{1}{2}$ inches plate. Considerations of economy in both time and plates prevented other views being taken, and for the reason that in an ulnar view it is difficult, and in many cases impossible, to get a side view of the line of fracture of the radius the amount of accurate information available from the present series is not complete. A side view of the wrist with the radius next the plate, under ordinary arrangement of apparatus, involves a more or less constrained position to a person suffering from this fracture, and it is thus very difficult to avoid some movement during the period of exposure. To overcome this difficulty I have devised a support for the wrist, plate, and tube with which it is not necessary to move the forearm while the two exposures are being made. For the radial side view the plate is placed vertically and the tube is lowered to the same level as the wrist which lies comfortably upon its support.

The preparation of a second series of cases in this way is now in progress, the results of which I propose to publish as soon as complete, and it is hoped that 200 cases may be collected within a reasonable time.

In making up Table I. it should be mentioned that a

\section{TABLE I.}

Pakt 1.

Total number of cases examined, 170

The radius only fractured ...

The ulna only fractured ...

Both bones fractured

Fracture of the trapezium

No fracture detected ...

Fracture of the

$\begin{array}{llllll}\text { Fracture of the styloid process of the ulna } & \ldots & \ldots & 88 & \text {, }\end{array}$ $\begin{array}{llllllll}\text { Separation of one or both epiphyses } & \ldots & \ldots & \ldots & \ldots & 11 & , "\end{array}$ Part 2.

The line of fracture of the radius-

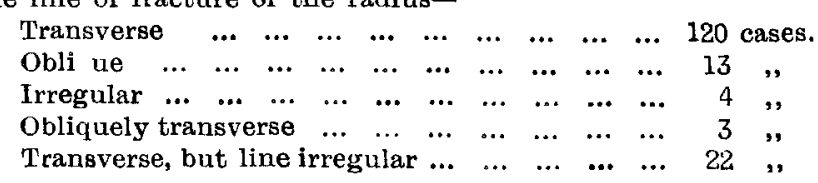

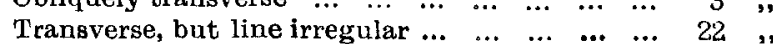

The average distance of.the line of fracture from the carpal border -

\begin{tabular}{|c|c|c|c|c|c|}
\hline$\frac{1}{8}$ inch & $2 c$ & ises. & $\frac{3}{4}$ inch & $\ldots$ & 11 cases. \\
\hline$\frac{1}{4} \quad \Rightarrow$ & ... 16 & $"$ & & $\ldots$ & 2 \\
\hline ," & ... 31 & , & 1支 inches & $\ldots$ & 1 case. \\
\hline , & ... 62 & ", & $1 \frac{1}{2} \quad$, & $\cdots$ & $1 "$ \\
\hline " & $\ldots \quad 17$ & ", & & & \\
\hline
\end{tabular}


Displacement of the lower fragment of the radius$\begin{array}{lllllllllll}\text { Inwards } & \ldots & \ldots & \ldots & \ldots & \ldots & \ldots & \ldots & \ldots & \ldots & \ldots\end{array}$

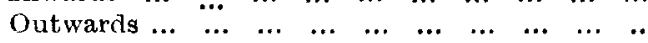

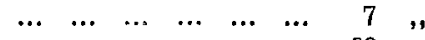
$\begin{array}{llllllllllrl}\text { Backwards } & \ldots & \ldots & \ldots & \ldots & \ldots & \ldots & \ldots & \ldots & \ldots & 60 & , \\ \text { Outwards and forwards } & \ldots & \ldots & \ldots & \ldots & \ldots & \ldots & 2 & \text {," }\end{array}$

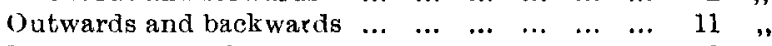

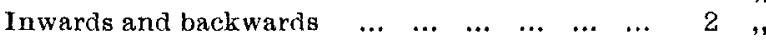
$\begin{array}{llllllll}\text { Impaction without comminution } & \ldots & \ldots & \ldots & \ldots & \ldots & 67 & \text {, }\end{array}$

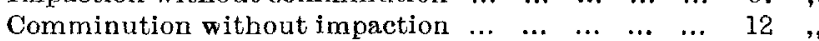
Impaction and comminution

separation of the epiphysis is counted as a transverse fracture and also that damage to the styloid prucess of the ulna is not counted as a fracture of that bone. Of the total number, 155 consisted of fractures of the radius only, but two cases occurring in which the ulna was alone fractured. In seven cases both bones were fractured, while in one other the only injury that could be detected was a fracture of the trapezium. No fracture could be detected in five cases in one of these there was some lipping of the carpal border of the radius due to ostenarthritis. Separation of one or both epiphyses occurred in 11 of the cases and three were complicated with a dislocation of the wrist-joint. The styloid process of the radius was cracked off in 20 cases, and this injury accounts for practically all those where the line of tracture was oblique, as well as for some of those which are described as "transverse but line irregular." Further, in all of these 20 cases the line of fracture ran into the joint. The wrist-joint was involved in 25 cases. This number includes the 20 cases above referred to and also some where the line of fracture was "irregular" or where there was comminution of the lower fragment. The frequency with which the styloid process of the ulna is torn off wholly or in part is very remarkable, occurring as it coes in more than half the total number of cases. If we take those cases where the radius only was fractured to constitute "Colles's fracture" this process is damaged more or less in 85 of the 155 cases, or 55 per cent. This percentage, however, will be found too low for injuries which are strictly "Colles's fractures," since amongst the 155 cases are included several of the styloid process of the radius and others which are not true "Colles's fractures."

Part 2 of Table I. refers to the lower end of the radius. Oat of the 162 cases in which this bone was broken the line of fracture was transverse or approximately at right angles to the line of the shaft in 120 , or 74 per cent. In all of those where the line of fracture was oblique, the line ran across the base of the styloid process and communicated with the joint. In those described as "irregular" there was considerable smashing of the end of the bone with no definite line in any particular direction. In two of those described as "obliquely transverse" the line of fracture lay across the bone otliquely without involving the joint. Among those where the fracture was "transverse but line irregular" were several in which the line was more or less curved with the convexity of the curve looking downwards. The average distance of the line of fracture from the carpal border was measured in all cases-those where the line was oblique and leading into the joint not being included in the table of measurements. The rapid rise in numbers from two at one-eighth of an inch to 62 at half an inch is very interesting, as is also the more rapid fall after this point is pissed. It will be seen that in no less than 111 out of a total of 155 cases the line of fracture is half an inch or less from the carpal border, just over 71 per cent., while in 31 only is the distance over half an inch -20 per cent.

In Erichsen's "Surgery," tenth edition, 1895, p. 598, it is said: "Gordon, who gave great attention to the mechanism of this fracture, states that in 27 old specimens examined by him the line of fracture post riorly varied from $\frac{3}{5}$ inch to $1 \frac{3}{4}$ inch, and anteriorly from 3 inch to 2 inches above the carpal border of the radius, being in ten 1 inch and under, in ten more than $1 \mathrm{inch}$, and in the others indefinable." It is interesting to compare these statements with the present series of fractures near the wrist where, out of a total of 155, in only two is the line of fracture over one inch above the carpal border.

The state of the lower fragment was a fertile source of discussion in the pre-Roentyen ray days. In the present series it will be seen that as regards displacement this takes place in a backward direction more than twice as often as all the other àisplacements taken together. In a large number of the cases there was no material displacement shown in the radiograph and in many of these there was impaction of

the upper into the lower fragment. Impaction was present in 88 cases-nearly 57 per cent.-21 of these being accompanied with comminution-comminution without impaction occurring in 12. Displacement upwards has not been recorded in this series. A certain amount always takes place when the lower fragment is displaced and tilted backwards, and also there is, of course, some shortening with impaction of the upper into the lower fragment. In none of the cases was there displacement upwards, such as occurs in a case of fracture of the middle of the shaft of the femur.

It will be remembered that in all the 170 cases such history and signs as could be elicited gave reasonable supposition of the existence of "Colles's fracture," and Table I. is valuable in showing what conditions may simulate this injury at times. Several of the cases are, of course, not "Colles's fractures," and in Table II. an attempt has been

TABLE II.

An Analysis of Radiograplic Negatives Ireparcd from 150 Cases of

The line of fracture-

$\begin{array}{lllllllllll}\text { Transverse } & \ldots & \ldots & \ldots & \ldots & \ldots & \ldots & \ldots & \ldots & \ldots & 110 \text { cases. }\end{array}$

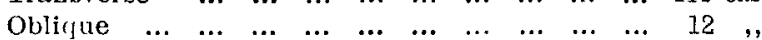

Irregular

Obliquely transverse

Transverse but line irregul

The distance from the carpal border-
$?$ inch
$\frac{1}{4}$, ,
2 cases.
$\begin{array}{llll}, & \ldots & 14 & \\ , & \ldots & 29 & ,\end{array}$
" $\quad \cdots 61$

Displacement of the lower fragment-

Inwards

Forwards

Backwards

Outwards and forwards $\ldots$

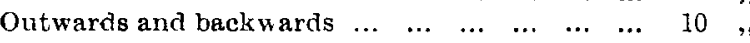

Inwards and backwards

Impaction without comminution

Comminution without impaction

Comminution and impaction

Dislocation of the wist complicating fracture...

Fracture of the styloid process of the radius $\quad \ldots \quad$...

Fracture communicating with the wrist-joint ...

Fracture of the styloid process of the ulna ...

made to prepare an analysis based only on such of the cases as conform to this injury. For this purpose only those where there was fracture of the lower end of the radius alone were taken, ignoring among others fracture of both bones and also separation of one or both epiphyses which leaves a total of 150 cases. This includes 11 cases where the line of fracture ran across the base of the styloid process of the radius communicating with the joint and having no displacement worth noting, certainly none that could have been detected clinically. This number can be deducted from the total and also from the figures relating to the styloid process of the radius and those of the fractures communicating with the wrist-joint if it is felt that they should not be included when calculating percentages, but it must be remembered that they were "Colles's fractures" from the clinical point of view.

My best thanks are due to the receiving-room officers and to the assistants in the electrical department for their kind assistance in collecting these cases.

Queen Anne-street, W.

\section{NOTE ON THE USE OF ACETO-SALICYLIC ACID IN RHEUMATIC ENDO- PERICARDITIS.}

BY EDWARD C. B. IBOTSON, M.B. LOND,

THE patient whose case is now described was in the third week of her third attack of rheumatic fever when $I$ was called to her on Nov. 3rd, 1906. She was nearly 16 years of age, thin and anæmic, with very dark hair and irides. There was no family history of rheumatism. The joints were not much affected. Loud pericardial friction sounds with well-marked to-and-fro bruit masking an endocardial presystolic bruit were heard. There were well-marked dulness and tubulas breathing below the left scapula 